\title{
GNSS Acquisition Performance of Short Spreading Codes
}

Christoph Enneking, Felix Antreich, André L. F. de Almeida

German Aerospace Center (DLR)

Institúto Technológico de Aeronautica (ITA)

Federal University of Ceará (UFC) 


\section{Outline}

-What are short spreading codes? Why are they interesting for acquisition?

- Part 1: statistical acquisition performance models for short codes

- Part 2: signal design - selecting a code length 


\section{Signal Acquisition is a resource-hungry process}

- 2-D search grid of code-phase/Doppler-freq.

- Extend spreading code (=PRN code) length $\rightarrow$ more code bins

- Extend coherent integration time $\rightarrow$ more Doppler bins

- Generation of test statistics costs memory/energy/time

- Statistical detection problem with possible errors:

- False alarm (satellite is actually not in-view)

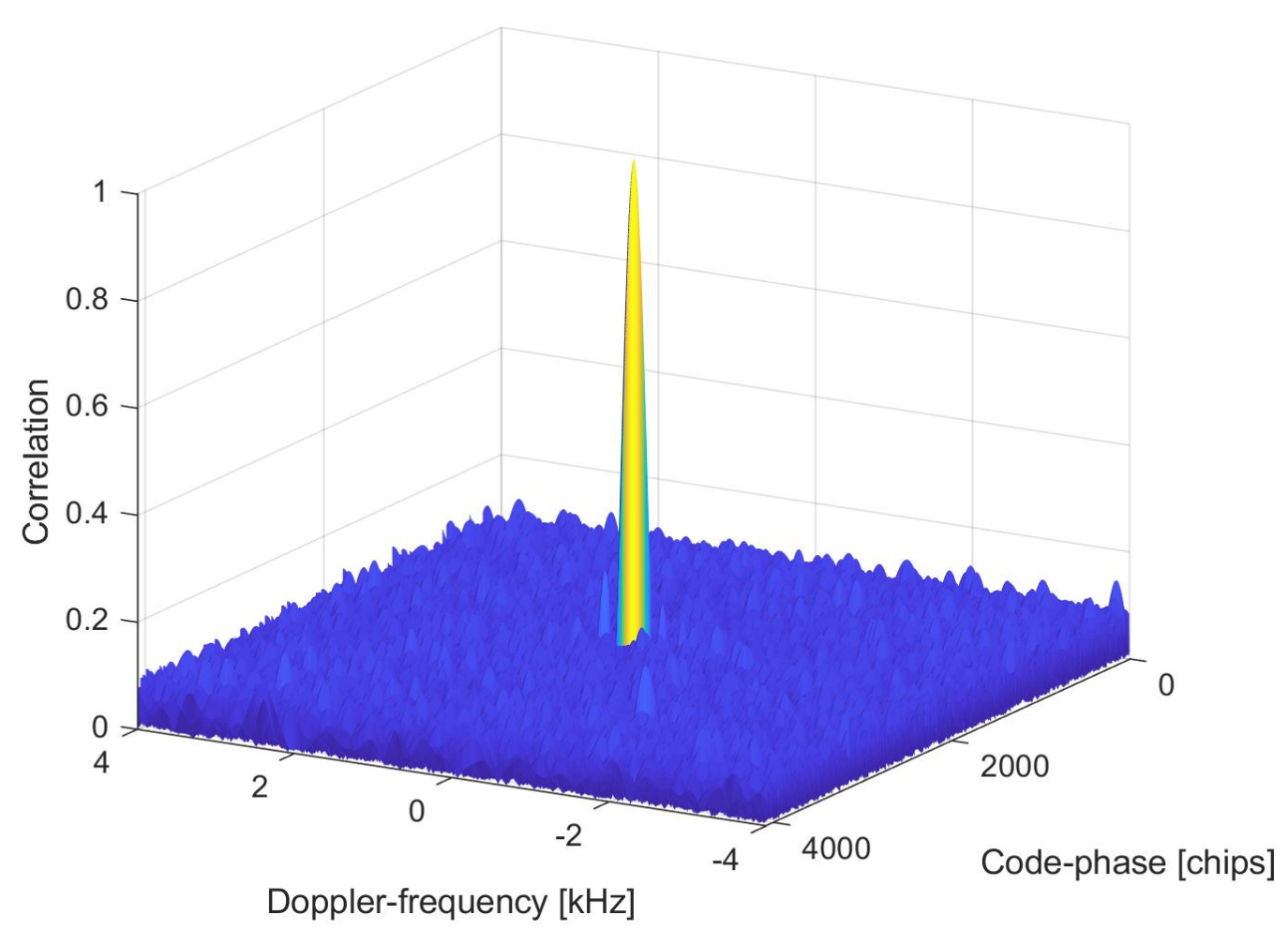

- Missed detection (satellite is not detected in the correct bin)

Doppler-frequency $[\mathrm{kHz}]$

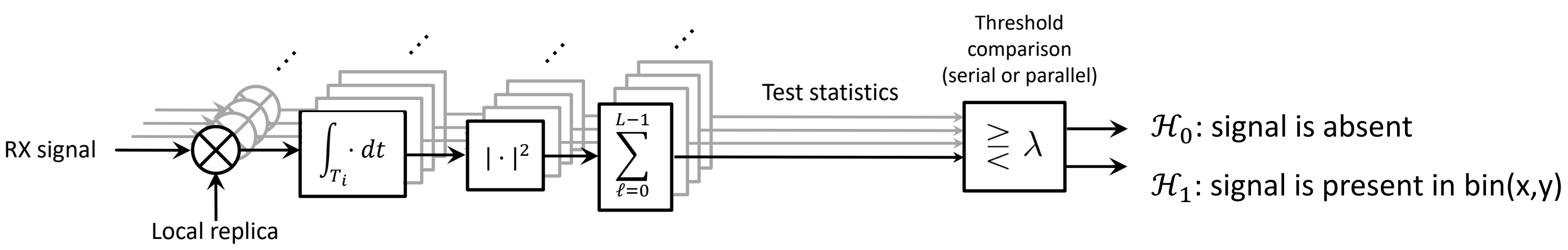




\section{Some examples}

*) assuming 40 correlations per ms ${ }^{* *}$ ) non-assisted, $-158.5 \mathrm{dBW} / 7 \mathrm{x}-153 \mathrm{dBW}$ IF

\begin{tabular}{|c|c|c|c|c|c|c|c|c|}
\hline Signal & $\begin{array}{l}\text { Coherent } \\
\text { integration }\end{array}$ & Doppler bins & $\begin{array}{c}\text { PRN code } \\
\text { length (chips) }\end{array}$ & $\begin{array}{l}\text { Code bins } \\
\text { per chip }\end{array}$ & $\begin{array}{l}\text { Overall } \\
\text { bins }\end{array}$ & $\begin{array}{l}\text { Required } \\
\text { time }\end{array}$ & $\begin{array}{c}\text { Data (or overlay) } \\
\text { bit rate }\end{array}$ & $\begin{array}{c}\text { Reliability } \\
P_{\text {DET }}\left(P_{F A}\right) * *\end{array}$ \\
\hline $\begin{array}{c}\text { GPS } \\
\text { L1 C/A }\end{array}$ & $4 \mathrm{~ms}$ & $\begin{array}{c}32 \\
(8 \mathrm{kHz} \times 4 \mathrm{~ms})\end{array}$ & 1023 & $\begin{array}{c}\mathbf{x 1} \\
\operatorname{BPSK}(1)\end{array}$ & $=\underline{32736}$ & $0.82 \mathrm{~s}$ & $50 \mathrm{~Hz}$ & $82 \%(5 \%)$ \\
\hline $\begin{array}{c}\text { Galileo } \\
\text { E1-C }\end{array}$ & $4 \mathrm{~ms}$ & 32 & 4092 & $\begin{array}{c}\mathbf{x} \\
\operatorname{BOC}(1,1)\end{array}$ & $=\underline{392832}$ & $9.82 \mathrm{~s}$ & $250 \mathrm{~Hz}$ & $66 \%(5 \%)$ \\
\hline
\end{tabular}

\section{RX 1: L1 C/A}

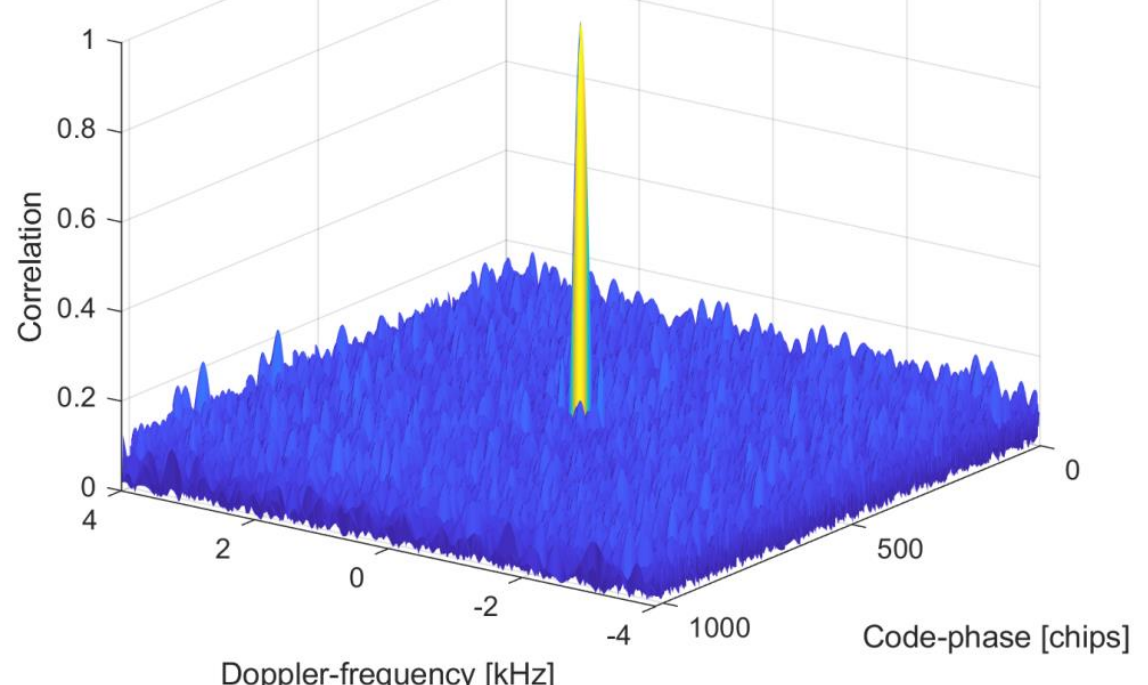

RX 2: E1-C

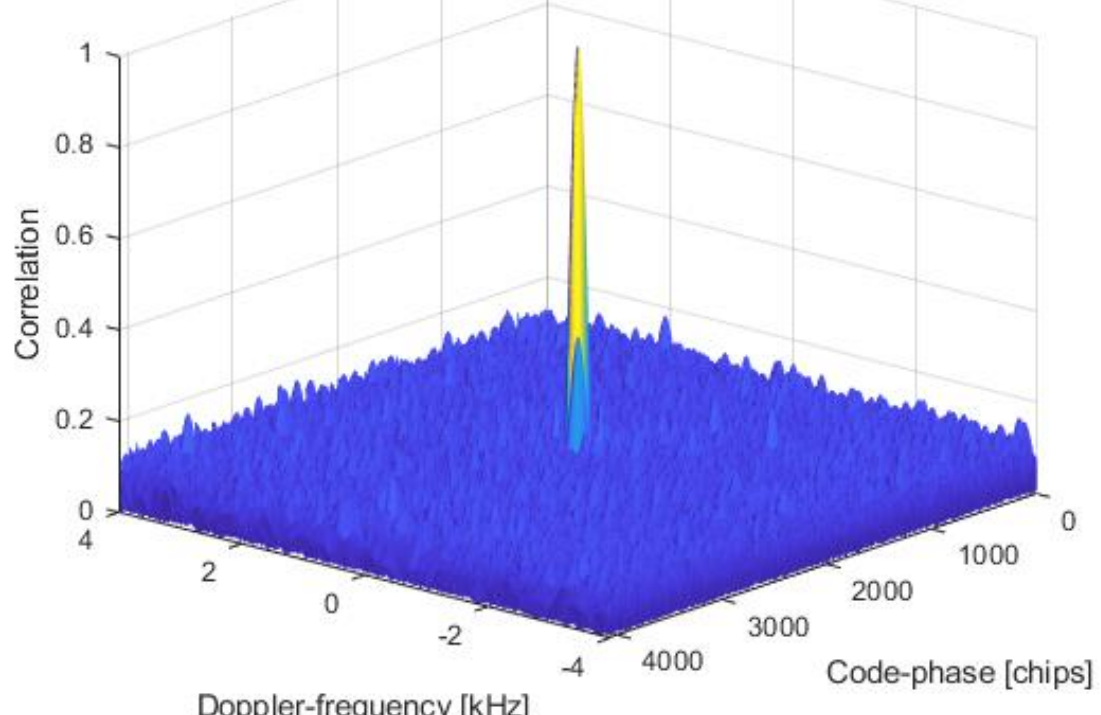




\section{Some examples}

${ }^{*}$ ) assuming 40 correlations per $\mathrm{ms}^{* *}$ ) non-assisted, $-158.5 \mathrm{dBW} / 7 \mathrm{x}-153 \mathrm{dBW}$ IF

\begin{tabular}{|c|c|c|c|c|c|c|c|c|}
\hline Signal & $\begin{array}{l}\text { Coherent } \\
\text { integration }\end{array}$ & Doppler bins & $\begin{array}{c}\text { PRN code } \\
\text { length (chips) }\end{array}$ & $\begin{array}{l}\text { Code bins } \\
\text { per chip }\end{array}$ & $\begin{array}{l}\text { Overall } \\
\text { bins }\end{array}$ & $\begin{array}{l}\text { Required } \\
\text { time }\end{array}$ & $\begin{array}{c}\text { Data (or overlay) } \\
\text { bit rate }\end{array}$ & $\begin{array}{c}\text { Reliability } \\
\boldsymbol{P}_{\text {DET }}\left(\boldsymbol{P}_{\boldsymbol{F A}}\right)^{* *}\end{array}$ \\
\hline $\begin{array}{c}\text { GPS } \\
\text { L1 C/A }\end{array}$ & $4 \mathrm{~ms}$ & $\begin{array}{c}32 \\
(8 \mathrm{kHz} \times 4 \mathrm{~ms})\end{array}$ & 1023 & $\begin{array}{c}\mathbf{x} 1 \\
\operatorname{BPSK}(1)\end{array}$ & $=\underline{32736}$ & $0.82 \mathrm{~s}$ & $50 \mathrm{~Hz}$ & $82 \%(5 \%)$ \\
\hline $\begin{array}{c}\text { Galileo } \\
\text { E1-C }\end{array}$ & $4 \mathrm{~ms}$ & 32 & 4092 & $\begin{array}{c}x 3 \\
\operatorname{BOC}(1,1)\end{array}$ & $=\underline{392832}$ & $9.82 \mathrm{~s}$ & $250 \mathrm{~Hz}$ & $66 \%(5 \%)$ \\
\hline
\end{tabular}

\section{RX 1: L1 C/A}

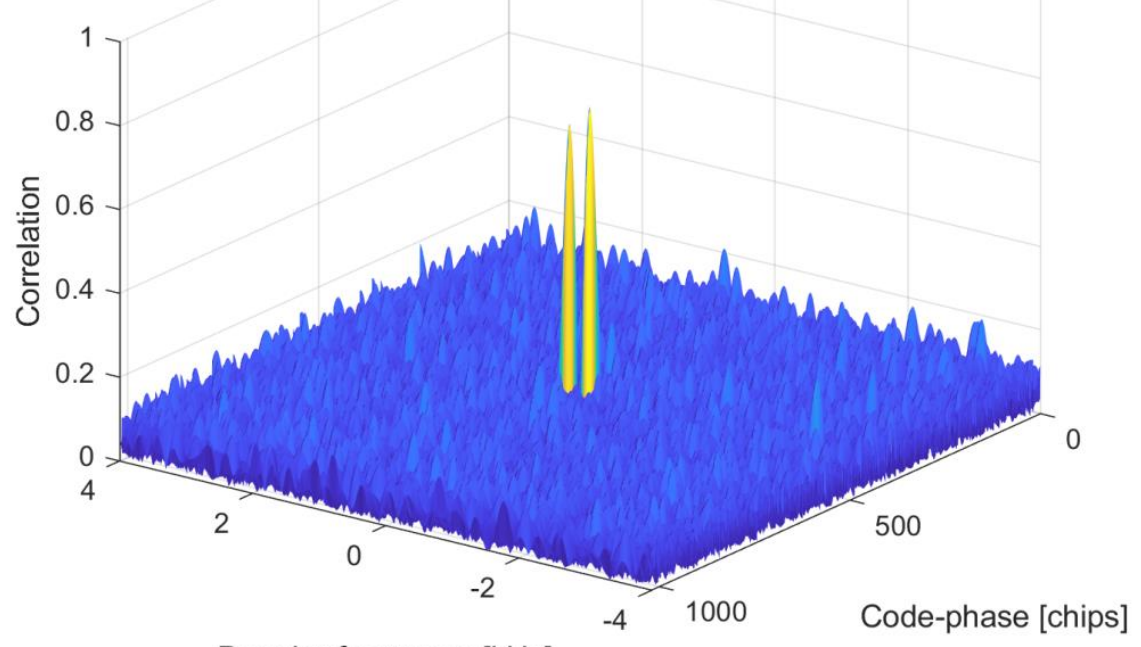

Doppler-frequency $[\mathrm{kHz}]$

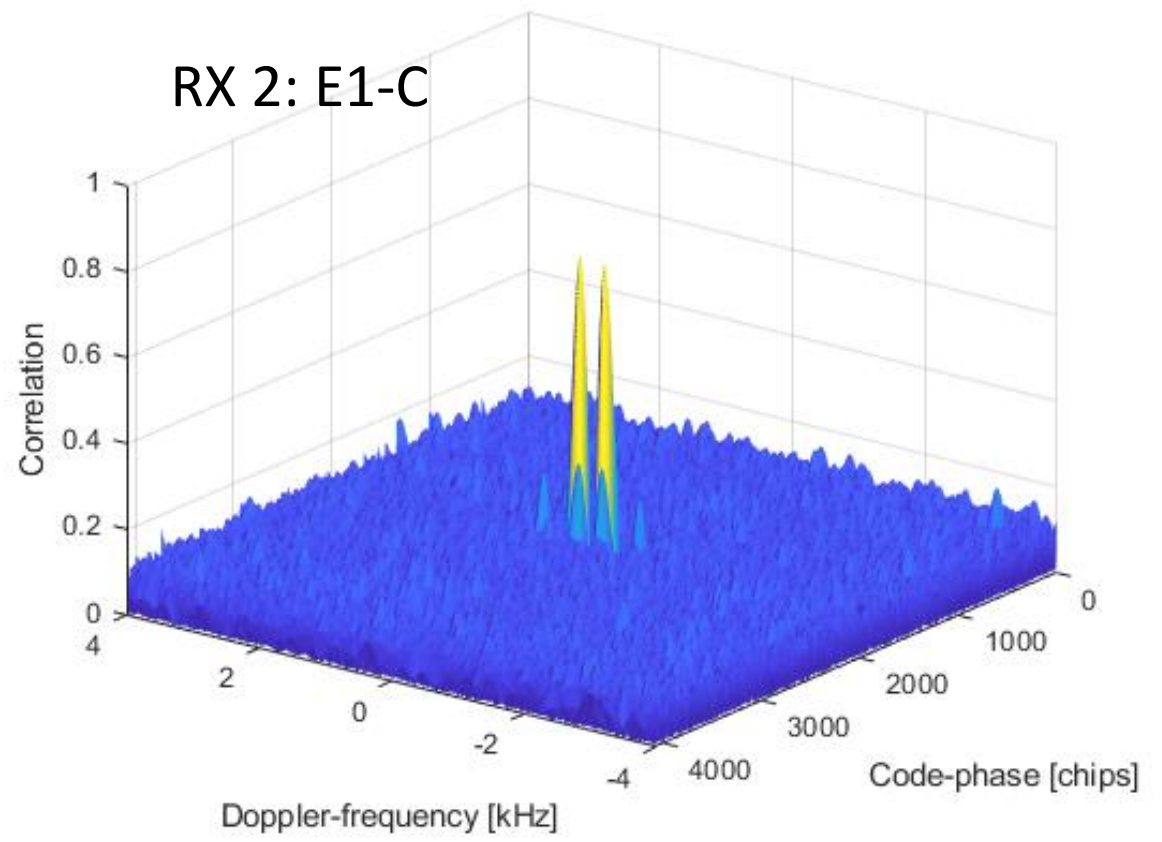

Bit transition in the middle of coherent integration interval 


\section{Civil GNSS signals ten years ago ... and today!}

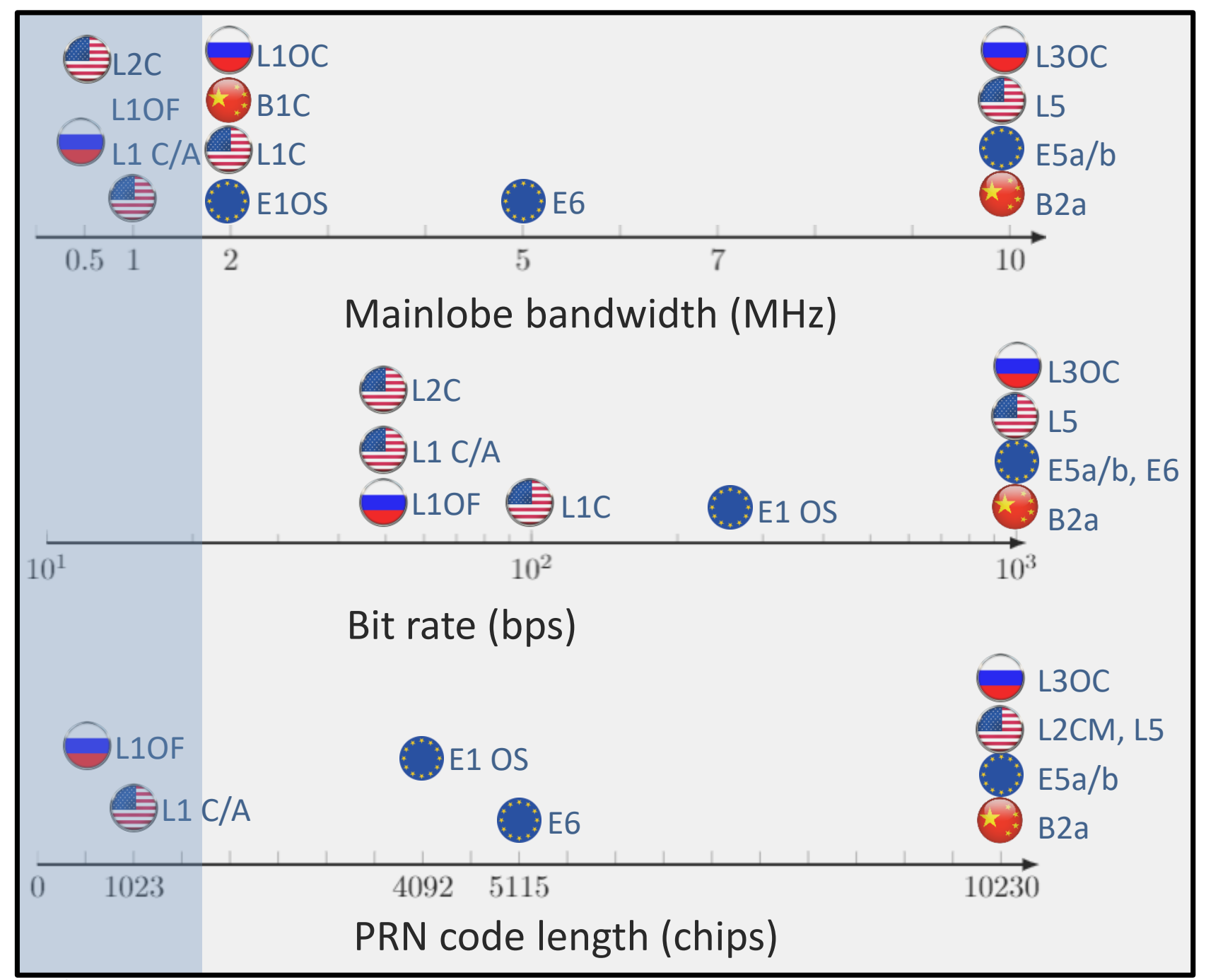

Trend in signal design 2000-2010:

"Race for accuracy"

- high bandwidth

- high bit rate (or overlay code, symbols,...)

- long PRN codes

Trend in signal design 2015-ongoing: "Fast fix/low cost"

- Time/energy per fix

- Snapshot receivers, loT devices, SpaceNav
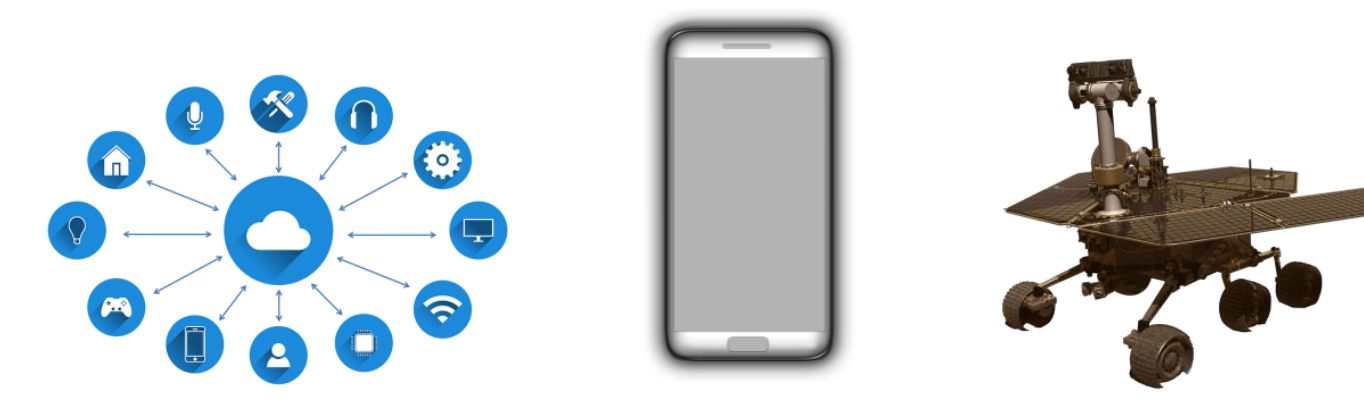


\section{A possible C/A Signal for Galileo: "E1-D"}

${ }^{*}$ ) assuming 40 correlations per $\mathrm{ms}^{* *}$ ) non-assisted, $-158.5 \mathrm{dBW} / 7 \mathrm{x}-153 \mathrm{dBW}$ IF

\begin{tabular}{|c|c|c|c|c|c|c|c|c|}
\hline Signal & $\begin{array}{l}\text { Coherent } \\
\text { integration }\end{array}$ & Doppler bins & $\begin{array}{c}\text { PRN code } \\
\text { length (chips) }\end{array}$ & $\begin{array}{l}\text { Code bins } \\
\text { per chip }\end{array}$ & $\begin{array}{l}\text { Overall } \\
\text { bins }\end{array}$ & $\begin{array}{l}\text { Required } \\
\text { time }\end{array}$ & $\begin{array}{c}\text { Data (or overlay) } \\
\text { bit rate }\end{array}$ & $\begin{array}{c}\text { Reliability } \\
P_{\text {DET }}\left(P_{F A}\right) * *\end{array}$ \\
\hline $\begin{array}{c}\text { GPS } \\
\text { L1 C/A }\end{array}$ & $4 \mathrm{~ms}$ & $\begin{array}{c}32 \\
(8 \mathrm{kHz} \times 4 \mathrm{~ms})\end{array}$ & 1023 & $\begin{array}{c}\mathbf{x} 1 \\
\operatorname{BPSK}(1)\end{array}$ & $=\underline{32736}$ & $0.82 \mathrm{~s}$ & $50 \mathrm{~Hz}$ & $82 \%(5 \%)$ \\
\hline $\begin{array}{c}\text { Galileo } \\
\text { E1-C }\end{array}$ & $4 \mathrm{~ms}$ & 32 & 4092 & $\begin{array}{c}\mathbf{x} \\
\operatorname{BOC}(1,1)\end{array}$ & $=\underline{392832}$ & $9.82 \mathrm{~s}$ & $250 \mathrm{~Hz}$ & $66 \%(5 \%)$ \\
\hline $\begin{array}{c}\text { Galileo } \\
\text { E1-D }\end{array}$ & $4 \mathrm{~ms}$ & 32 & $\begin{array}{c}341 \\
\text { or less }\end{array}$ & $\begin{array}{c}x 1 \\
\operatorname{BPSK}(1)\end{array}$ & $=\frac{10912}{\text { or less }}$ & $\begin{array}{l}0.27 \mathrm{~s} \\
\text { or less }\end{array}$ & $\begin{array}{l}50 \mathrm{~Hz} \\
\text { or less }\end{array}$ & ??? \\
\hline
\end{tabular}

- Code length of 341 would reduce the acquisition complexity by a factor of 3

- Is such an acquisition signal still reliable? 


\section{Outline}

- Why are short PRN codes interesting for acquisition?

- Part 1: statistical acquisition performance models for short PRN codes 


\section{A possible C/A Signal for Galileo: "E1-D"}

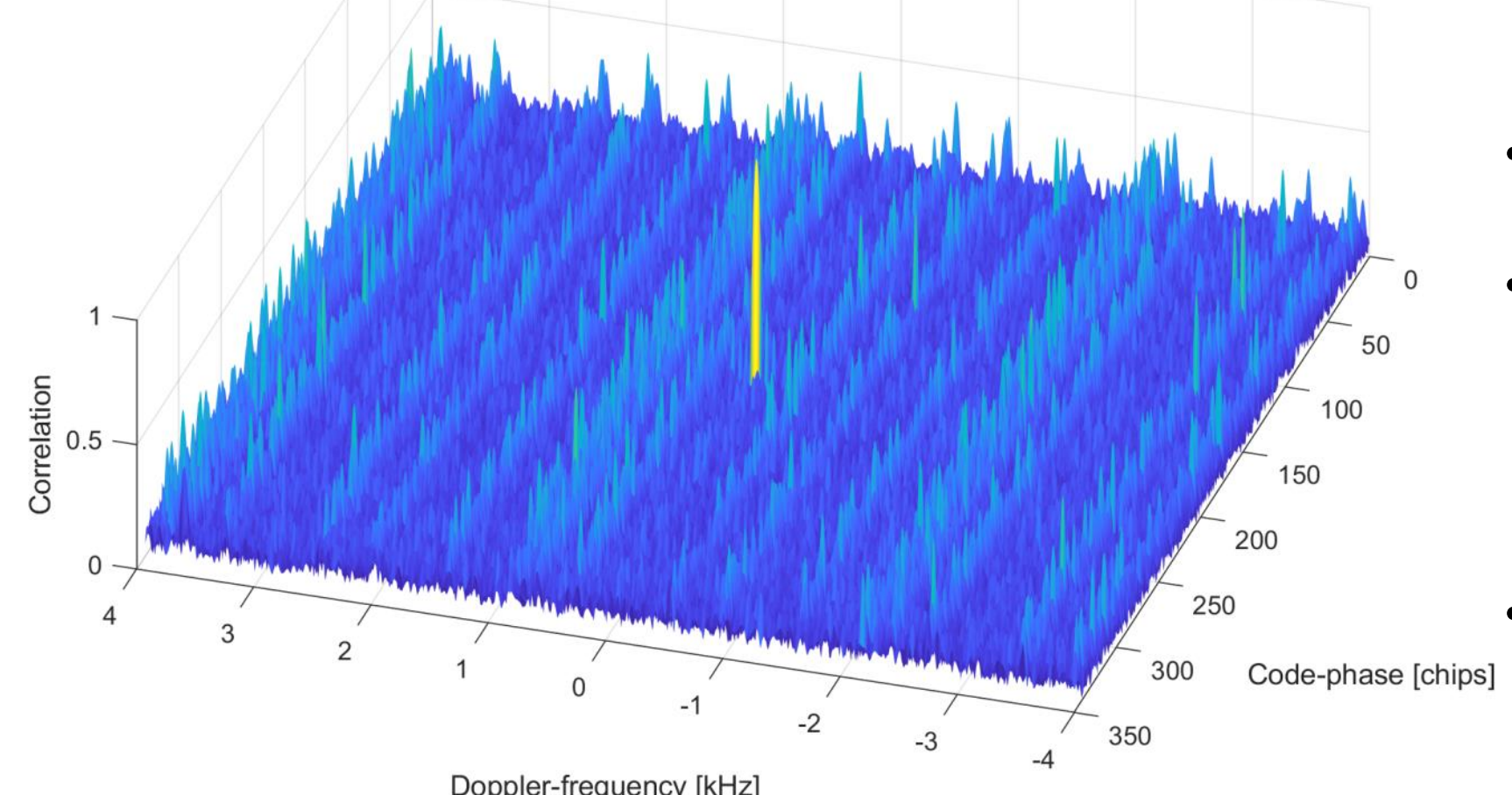

Doppler-frequency $[\mathrm{kHz}]$
- 8 in-view satellites transmitting E1-D (as in Slide 7)

- $k=1$ to be acquired (-158.5 dBW)

- $k=2, \ldots, 8$ interferers (-153 dBW)

- Interference affects some Doppler bins more than others

- Effect becomes more pronounced for

- near-far scenarios

- shorter codes

- lower databit rate

- This effect is known from L1 C/A, but less pronounced 


\section{State of the art: fine SSC}

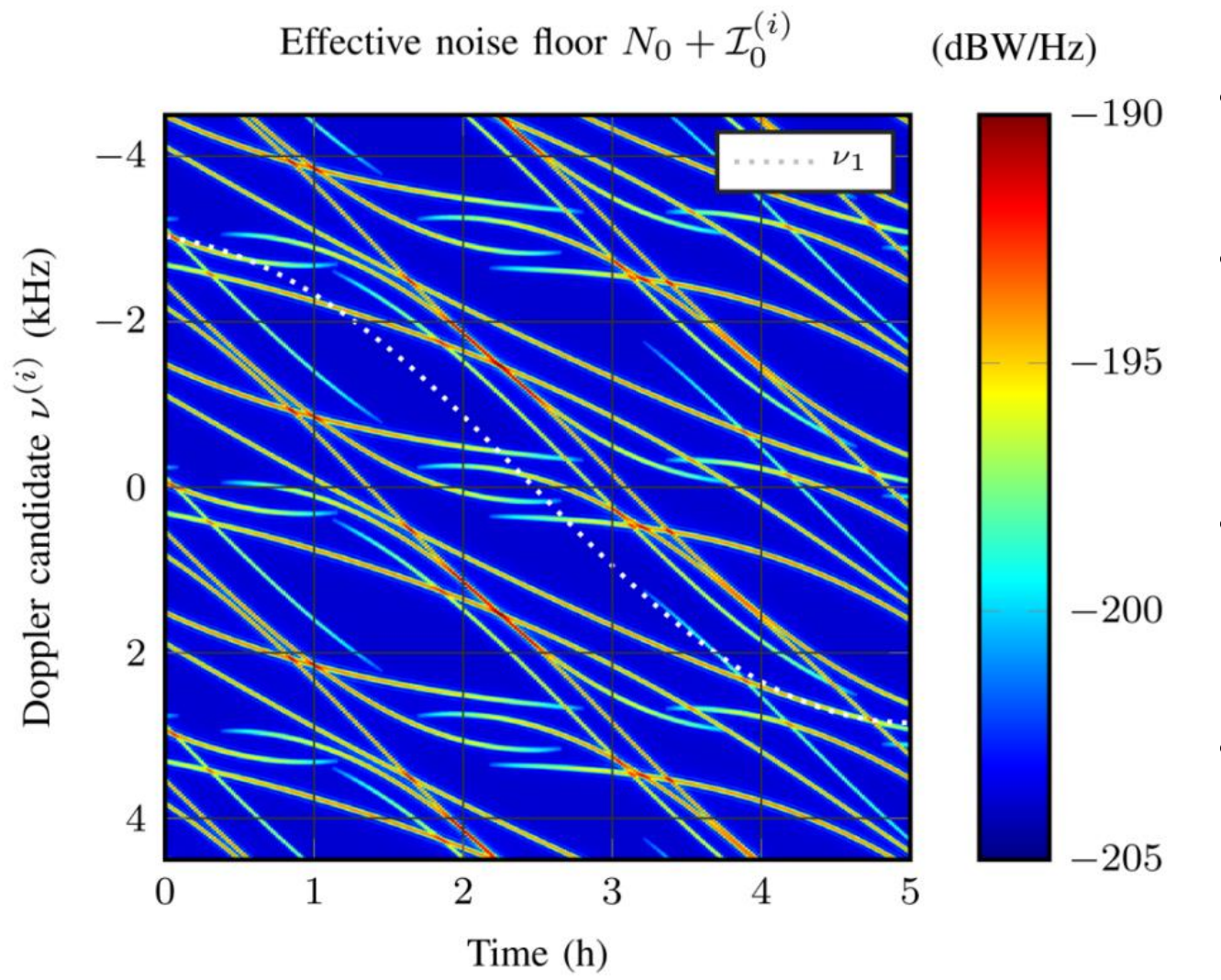

Figure: effective noise floor vs. Doppler bin vs. time for a Walker $(24 / 3 / 1)$ constellation transmitting E1-D (as in Slide 7)
- Spectral separation coefficient (SSC): $\beta_{1, k}^{(i)}=\int \phi_{1}^{(i)}(f) \phi_{k}(f) d f$

- The interference floor $I_{0}^{(i)}$ is a weighted sum of SSCs

$$
I_{0}^{(i)}=\sum_{k=2}^{K} P_{k} \beta_{1, k}^{(i)}, \quad P_{k} \text { : power of sat } k
$$

- Interference can be modeled as Gaussian noise, using an effective noise floor $N_{0}+I_{0}^{(i)}$

- Two SSC-versions

1. Coarse SSC (low-res. spectrum features: order of $\mathrm{MHz}$ ) = const.

2. Fine SSC (high-res. spectrum features: order of sub-kHz)

- The results on the left are based on the fine SSC [Heg2019], [Dri2012] $\rightarrow$ SSCs vary from bin to bin! 


\section{State of the art: fine SSC (cont'd)}

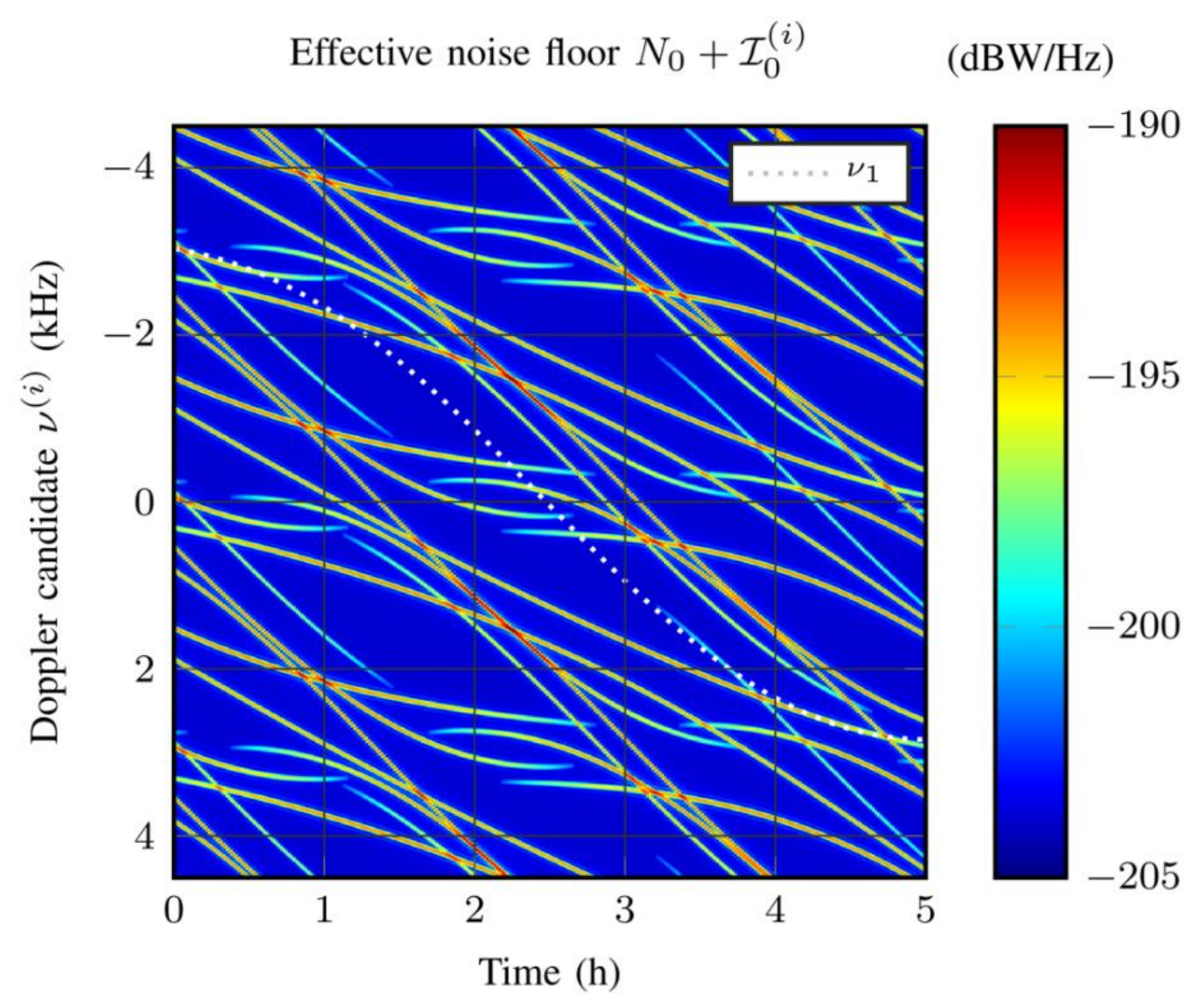

- Fine SSC is large if the relative Doppler $v_{k}-v^{(i)}$ between the interferer $k$ and bin $i$ is a multiple of the PRN repetition rate $3 \mathrm{kHz}(\mathrm{L} 1 \mathrm{C} / \mathrm{A}: 1 \mathrm{kHz}$ )

- Sometimes, several such "Doppler crossings" occur in one bin at the same time (effective noise floor goes up by $15 \mathrm{~dB}$ )

- Straightforward (exact) solution: calculate bin probabilities $p_{\mathrm{fa}}^{(i)}, p_{\mathrm{det}}^{(i)}$ in Gaussian noise for

- each fine SSC between every bin $i$ and every interferer $k$

- each possible constellation

- each possible detection threshold

then calculate global probabilities, e.g. $P_{\mathrm{FA}}=1-\prod_{i=1}^{N_{\text {bins }}}\left(1-p_{\mathrm{fa}}^{(i)}\right)$.

This is too complex for the evaluation of one signal design candidate! 


\section{Simplified model: random SSC}

- Given the instantaneous fine SSCs between all signals and bins, the bin probability of false alarm would be

$$
p_{\mathrm{fa}}^{(i)}=e^{-\frac{\lambda}{N_{0}+I_{0}^{(i)}}} \quad \lambda \text { : detection threshold }
$$

- Idea: do NOT calculate $I_{0}^{(i)}$ for each bin, but treat it as random variable i.i.d. for all bins with distribution $f_{\mathcal{I}_{0}}\left(\mathcal{I}_{0}\right)$

- Calculate the compound bin probability of false alarm, for random $\mathcal{I}_{0}$

$$
p_{\mathrm{fa}}=e^{-\frac{\lambda}{N_{0}+\mathcal{I}_{0}}}
$$

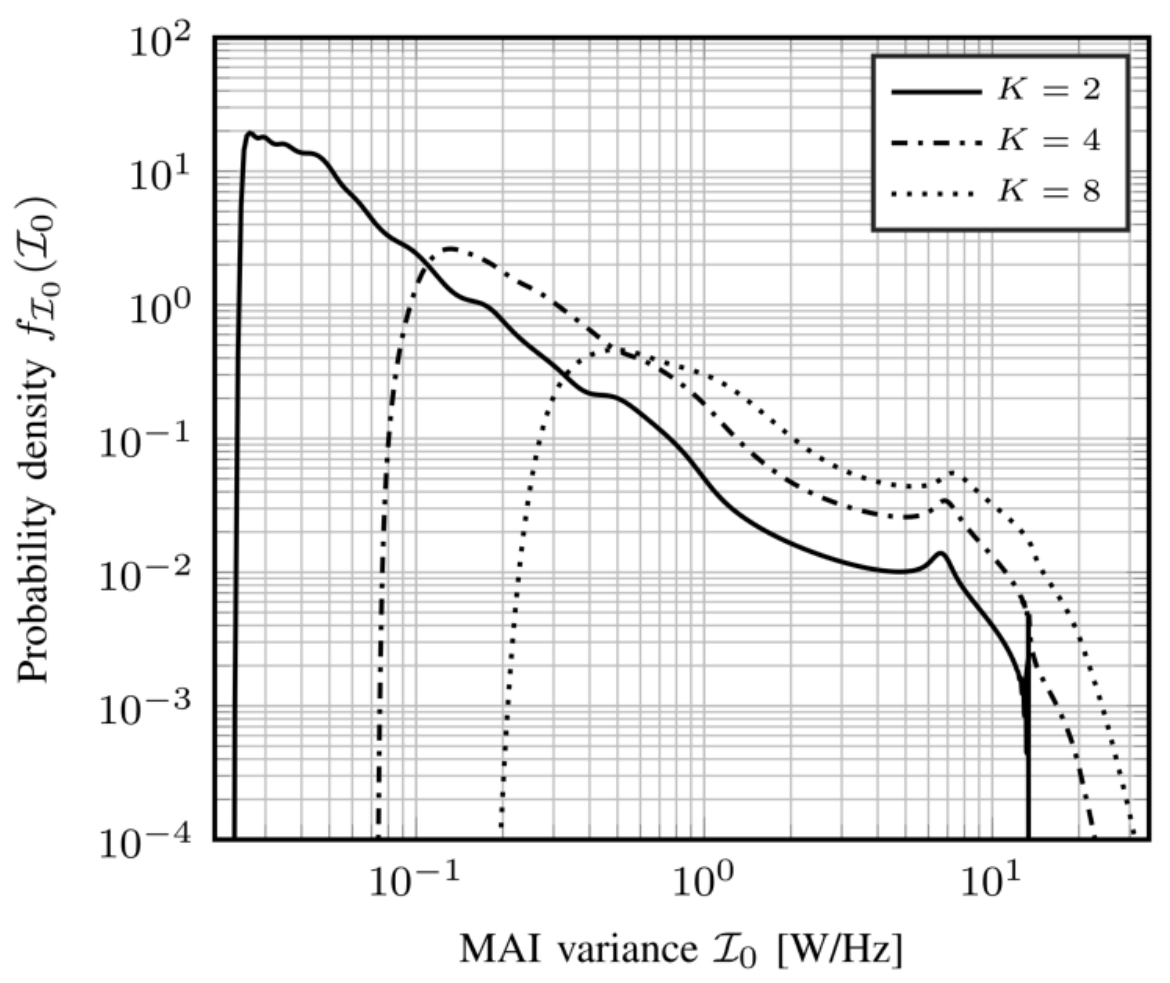

$K$ : number of in-view satellites 


\section{Compound bin probabilities}

- The compound bin probability of false alarm

- is independent of the bin index $i$

- is representative for all search bins, but not for any particular search bin

- is a mixture-Gaussian model (not a line on semilog axis!)

- The global probability of false alarm simplifies to

$$
P_{\mathrm{FA}}=1-\prod_{i=1}^{N_{\text {bins }}}\left(1-p_{\mathrm{fa}}^{(i)}\right) \approx 1-\left(1-p_{\mathrm{fa}}\right)^{N_{\text {bins }}}
$$

$\rightarrow$ This facilitates acquisition signal design considerably!

- The bin probability of detection is hardly affected by

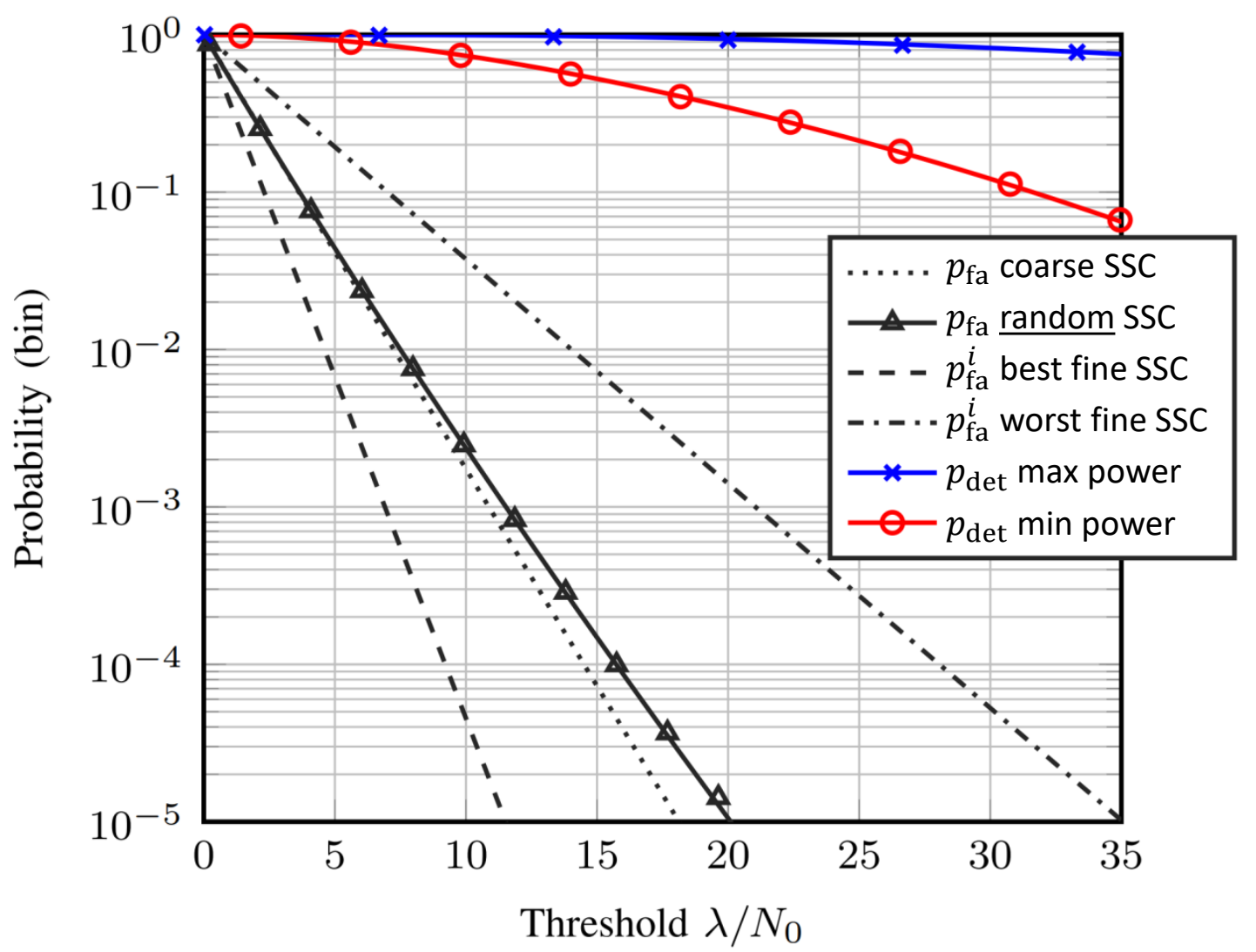
interference $\rightarrow$ use an accurate model, e.g. [Dri2007] 


\section{Outline}

- Why are short PRN codes interesting for acquisition?

- Part 1: statistical acquisition performance models for short PRN codes

- Part 2: signal design - selecting a code length 


\section{Receiver operating characteristic (ROC) curve}

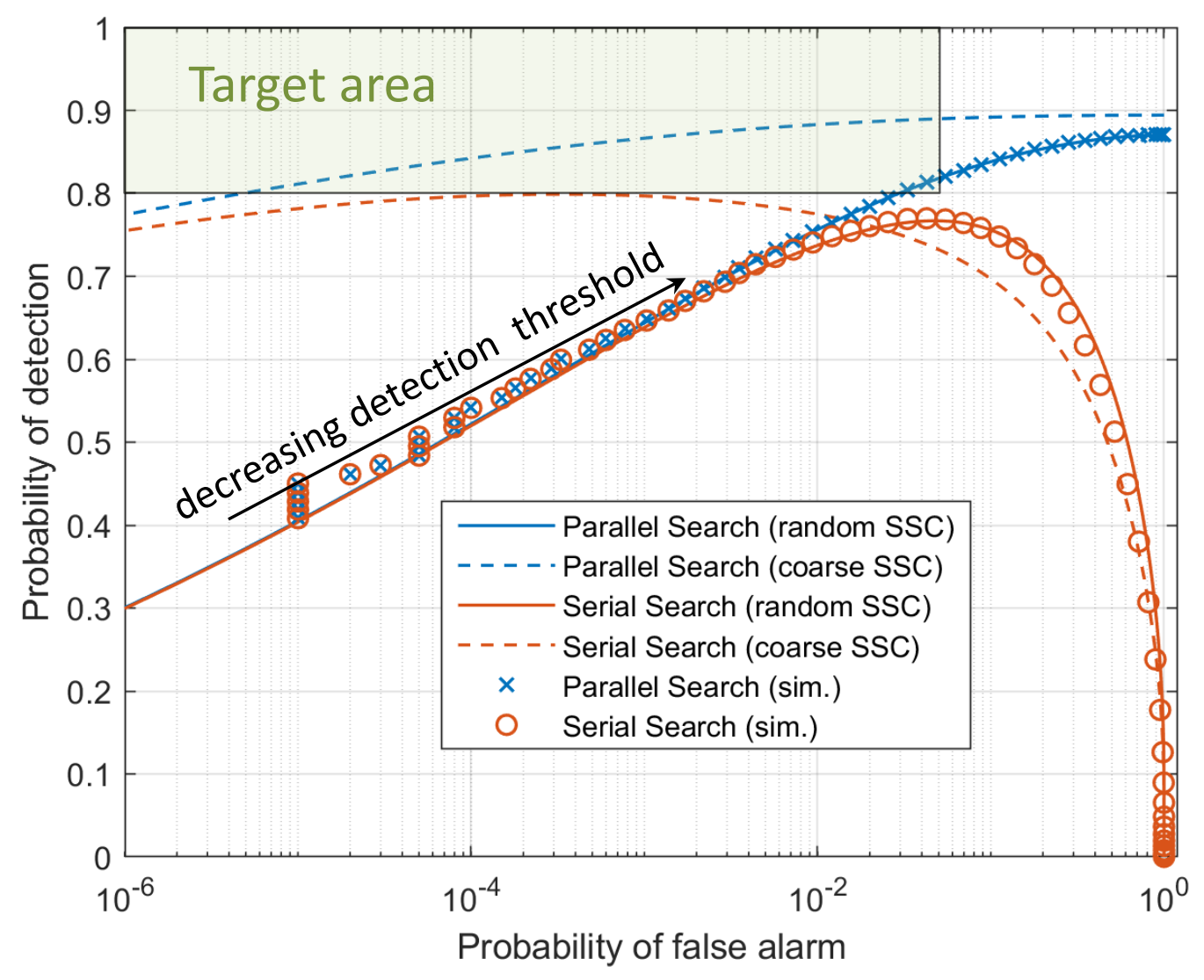

\begin{tabular}{|c|c|}
\hline Code length & 341 \\
\hline Bit rate & $0 \mathrm{~Hz}$ (pure pilot) \\
\hline Modulation & BPSK(1) \\
\hline Coh. Integration & $4 \mathrm{~ms}$ \\
\hline Search bins & $32 \times 341=10912$ \\
\hline Signal of interest & $-158.5 \mathrm{dBW}$ (minimum) \\
\hline Interferers & $7 \times-153.0 \mathrm{dBW}$ (maximum) \\
\hline Noise floor & $-204.0 \mathrm{dBW} / \mathrm{Hz}$ \\
\hline Doppler spread & $-4 \mathrm{kHz} . .4 \mathrm{kHz}$ \\
\hline Target $P_{\mathrm{DET}}$ & $>80 \%$ \\
\hline Target $P_{\mathrm{FA}}$ & $<5 \%$ \\
\hline
\end{tabular}




\section{Sensitivity vs. code length}

Given a scenario...

- tentative code length

- coherent integration time

- number and power of interferers $k=2, \ldots, K$

and target global probability ...

- of detection

- of false alarm,

what is the required received power for the satellite signal to be acquired, $k=1$ ?

\begin{tabular}{|c|c|}
\hline Integration time & $4 \mathrm{~ms}$ \\
\hline In-view satellites & 8 \\
\hline Power per interferer & $-153 \mathrm{dBW}(\mathrm{max})$ \\
\hline Probability of detection & $>80 \%$ \\
\hline Probability of false alarm & $<5 \%$ \\
\hline
\end{tabular}

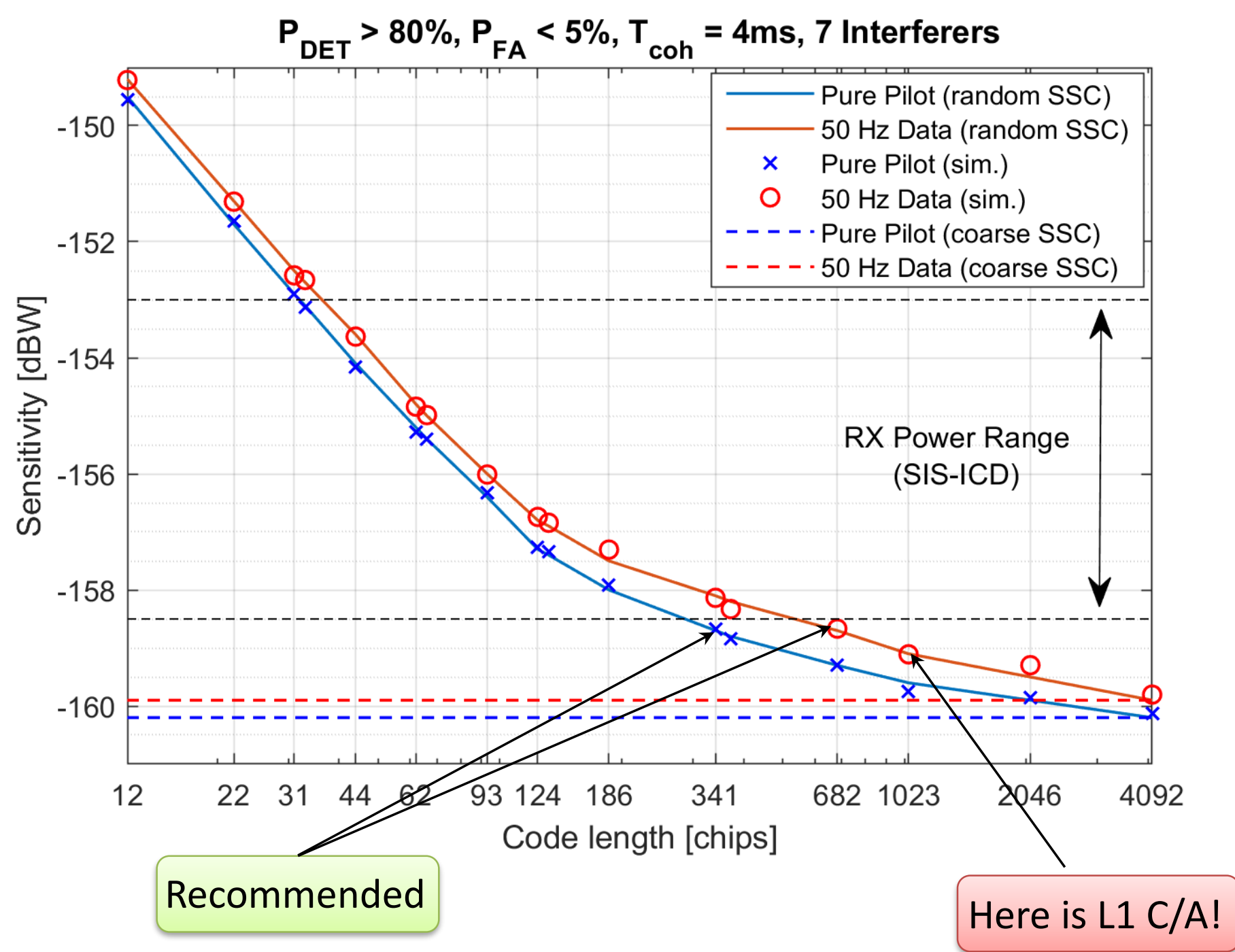




\section{Conclusion}

- New C/A-signals with codes shorter than 1023 (e.g. 341) chips are an option for low-cost acquisition, especially for Galileo

- Self-interference needs to be assessed

- New model (random SSC \& compound bin probabilities) has been developed for accurate global probability of false alarm $\Leftrightarrow$ state of the art:

- Coarse SSC: very inaccurate for C/A-signals

- Fine SSC: more accurate, but too complex for acquisition signal design

- $50 \mathrm{~Hz}$ bit sequence leads to acceptable sensitivity loss (0.3-0.5 dB as compared with pure pilot)

- Final design options:

\begin{tabular}{|c|c|c|c|c|c|c|c|}
\hline Signal & Coh. Int. & Doppler bins & Code bins & Overall bins & Required time & Bit rate & $P_{D E T}\left(P_{F A}\right)$ \\
\hline L1 C/A & $4 \mathrm{~ms}$ & 32 & 1023 & $=\underline{32736}$ & $0.82 \mathrm{~s}$ & $50 \mathrm{~Hz}$ & $82 \%(5 \%)$ \\
\hline E1-D Pure Pilot & $4 \mathrm{~ms}$ & 32 & 341 & $=\underline{10912}$ & $0.27 \mathrm{~s}$ & $\mathrm{OHz}$ & $82 \%(5 \%)$ \\
\hline E1-D Quasi Pilot & $4 \mathrm{~ms}$ & 32 & 682 & $=\underline{21824}$ & $0.54 \mathrm{~s}$ & $50 \mathrm{~Hz}$ & $81 \%(5 \%)$ \\
\hline
\end{tabular}




\section{References}

[Heg2020] C. Hegarty, “A simple model for GPS C/A-code self-interference”, ION Navigation, Jan. 2020.

[Dri2012] C. O'Driscoll, J. Fortuny-Guasch, "On the determination of C/A code self-interference with application to RFC analysis and pseudolite systems", Proc. Int. Tech. Meeting Inst. Nav. ION/GNSS, Nashville, TN, Sep. 2012.

[Dri2007] C. O'Driscoll, "Performance analysis of the parallel acquisition of weak GPS signals", PhD Thesis, National University of Ireland, Cork, 2007.

[Enn2018] C. Enneking, F. Antreich, André L. F. de Almeida, "Gaussian Approximations for Intra- and Intersystem Interference in RNSS", IEEE Comm. Letters, Jul. 2018.

[Enn2019] - , "Pure Pilot Signals for GNSS: How Short Can We Choose Spreading Codes?", ION ITM 2019, Reston, Virginia, Jan. 2019.

\section{Thank you for your attention!}




\section{Model usage - Step 1: Identify TX and RX parameters}

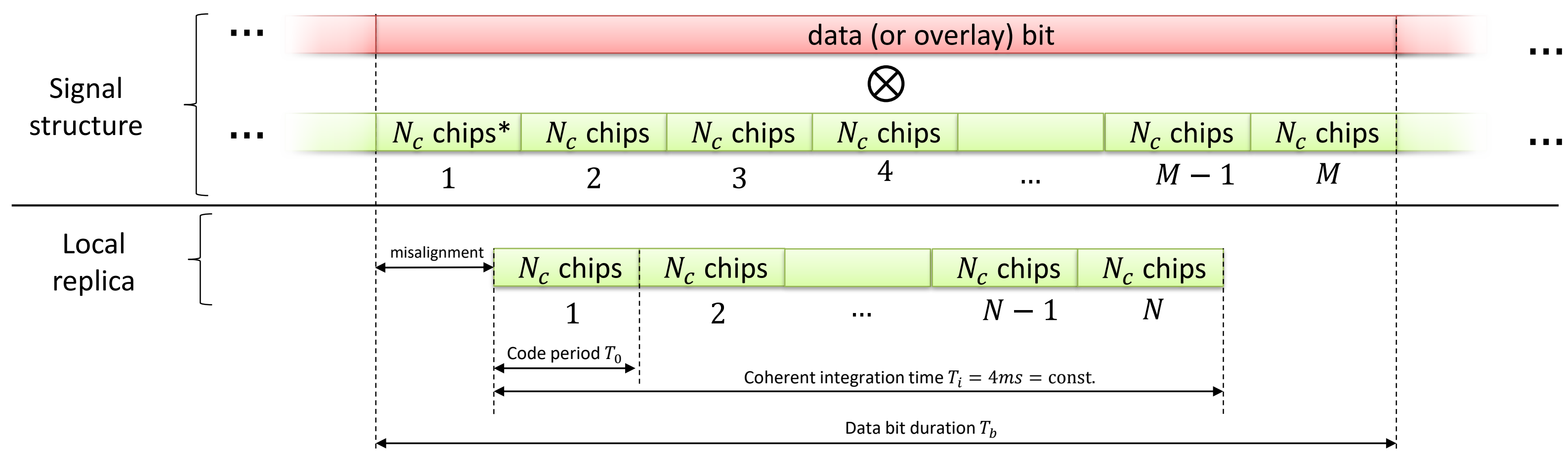

\begin{tabular}{|c|c|c|c|c|}
\hline & Signal & Galileo E1-C & GPS L1 C/A & Galileo E1-D \\
\hline \multirow{2}{*}{ TX parameters } & Code length: $N_{c}$ & 4092 & 1023 & 341 \\
\hline & PRNs per bit: $M$ & 1 & 20 & 60 \\
\hline RX parameter \{ & PRNs per integration: $N$ & 1 & 4 & 12 \\
\hline
\end{tabular}




\section{Model usage - Step 2: Calculate probability density function of fine SSC}

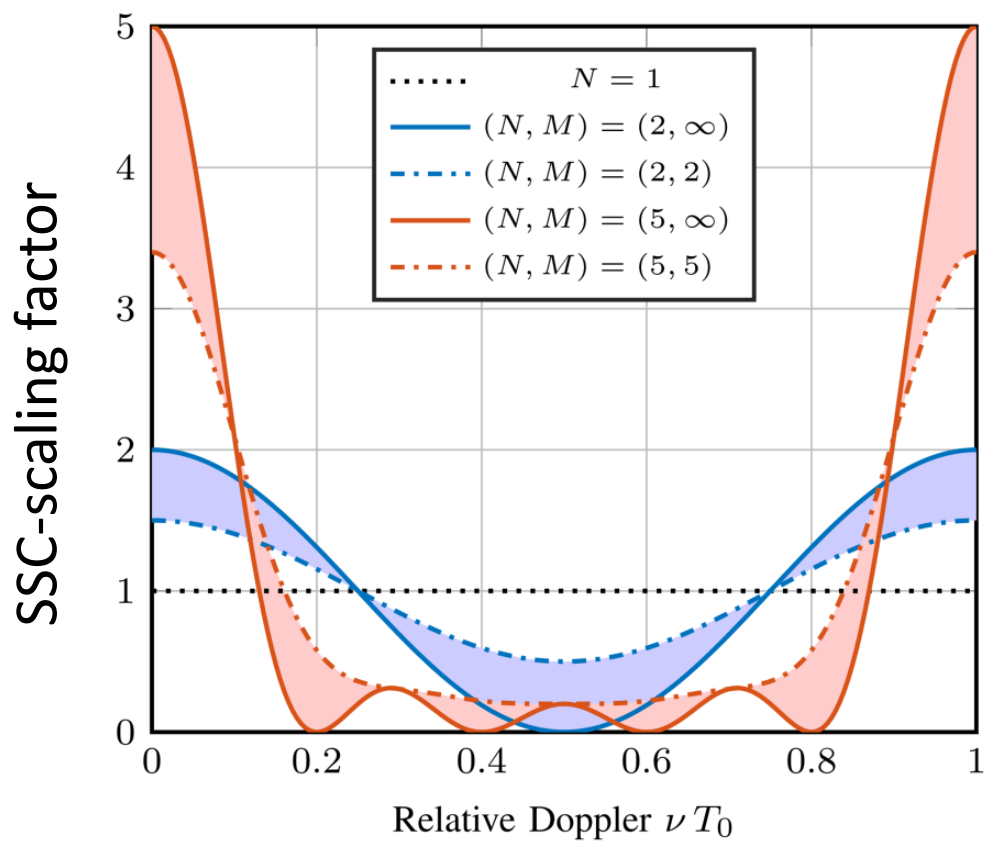

Figure top: Fine SSC vs. Doppler for TX parameter M and RX parameter N

Figure right: PDF of (dimensionless) fine SSC for uniform delay/Doppler [Enn2018]
- Use fine SSC-models for Doppler $v$ [Heg2020] and (optionally) delay $\tau$

- It is sufficient to consider the intervals

$$
v \in\left[0, \frac{1}{T_{0}}\right], \tau \in\left[0, T_{c}\right]
$$

- Bin the resulting fine SSCs to obtain the PDF of the fine SSC

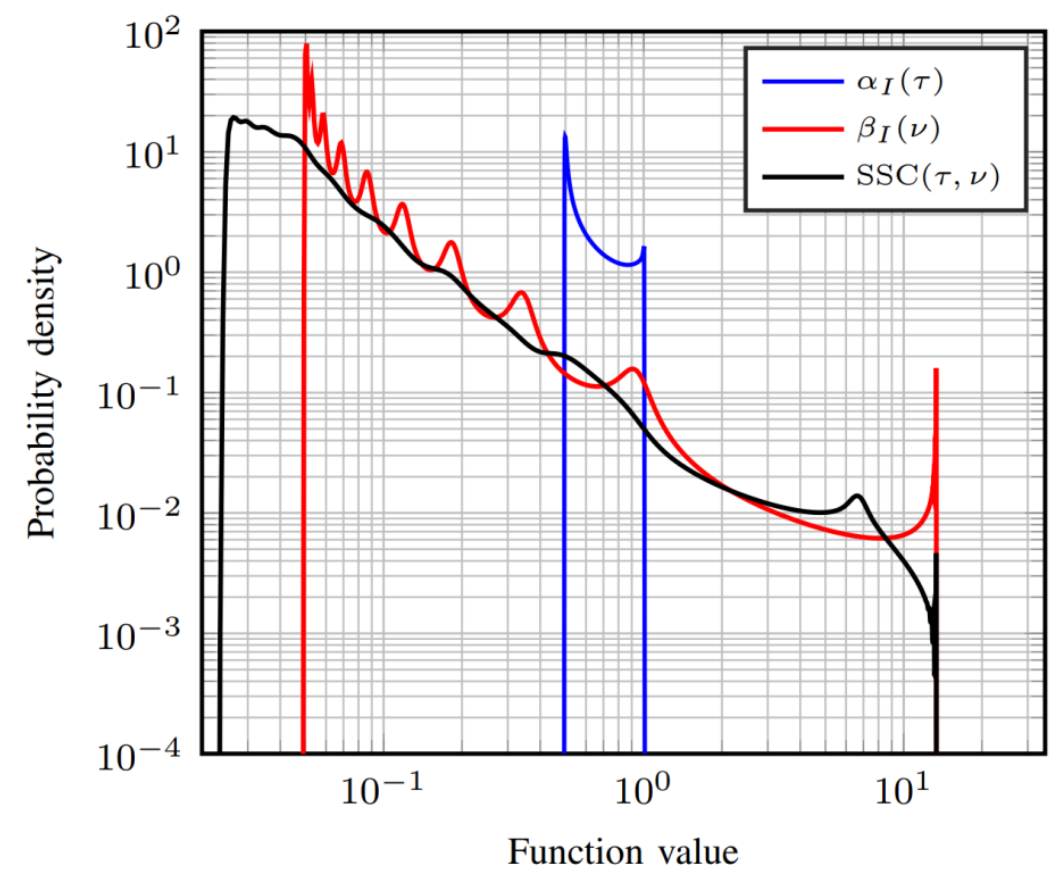




\section{Model usage - Step 3: Convolutions}

- Weight with the received powers $P_{k}$, and perform $K-2$ convolutions (for $K-1$ interferers)

$$
f_{I_{0}}\left(I_{0}\right) * \cdots * f_{I_{0}}\left(I_{0}\right)
$$

- Now, the PDF of the interference floor is obtained

- Good alternative: sample the PDF directly from constellation simulations, using [Heg2020]

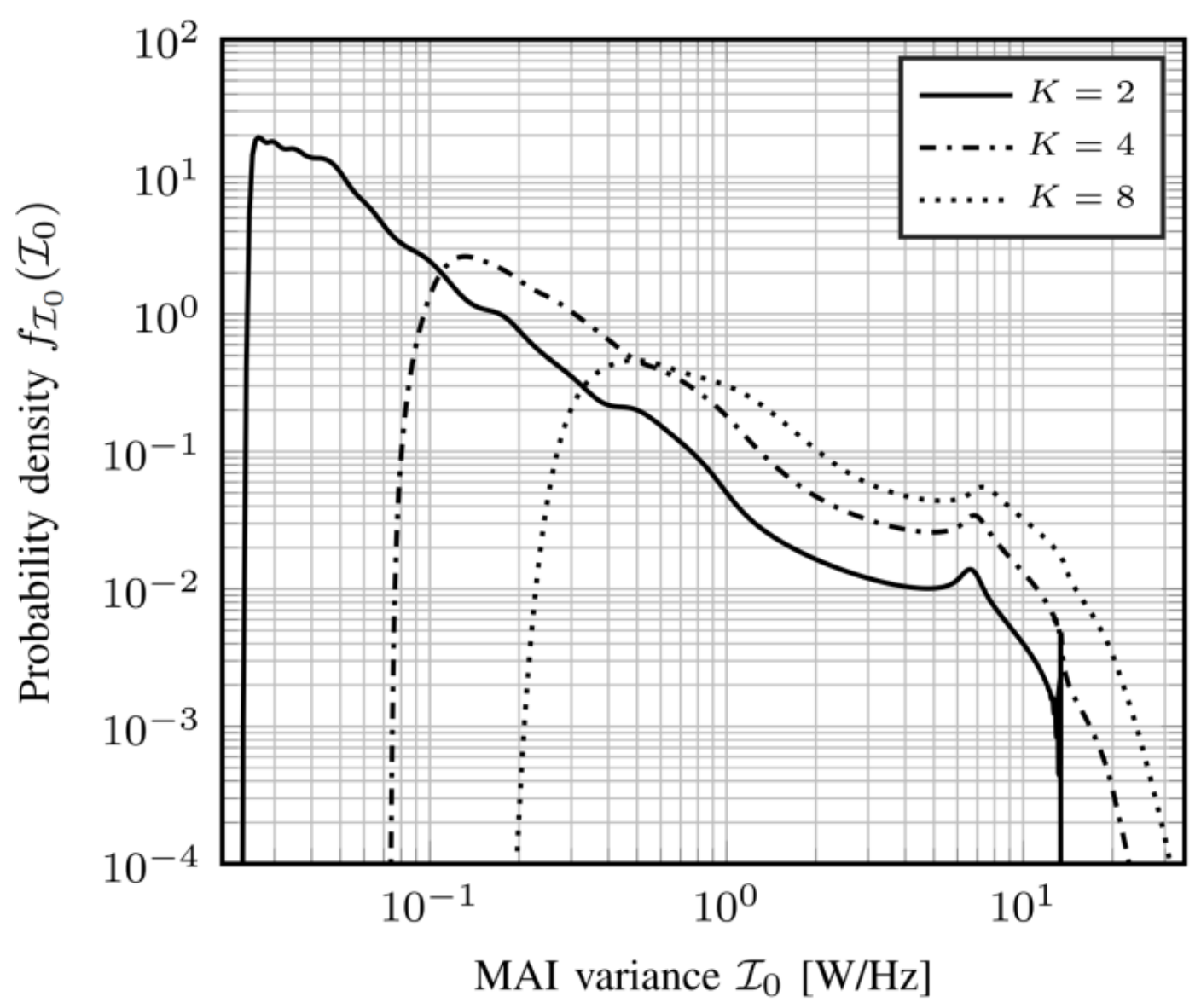

Figure: PDF of interference floor for $K-1$ interferers with unit power 


\section{Model usage}

For more details on this model, stay tuned for our forthcoming journal paper:

C. Enneking, F. Antreich, André L. F. de Almeida

"Receiver Operating Characteristic of GNSS Coarse/Acquisition Signals With Short Codes", approx. end of 2020. 


\section{Acknowledgment}

This work has been carried out within the framework of the project "R\&D for maritime safety and security and corresponding real time services" led by the Program Coordination Defence and Security Research within the German Aerospace Center (DLR). 